\title{
Saliva IgM and IgA Are a Sensitive Indicator of the Humoral Immune Response to Escherichia coli 0157 Lipopolysaccharide in Children with Enteropathic Hemolytic Uremic Syndrome
}

\author{
KERSTIN LUDWIG, ENKE GRABHORN, MARTIN BITZAN, CHRISTOPH BOBROWSKI, \\ MARKUS J. KEMPER, INGO SOBOTTKA, RAINER LAUFS, \\ HELGE KARCH, AND DIRK E. MÜLLER-WIEFEL
}

Klinik und Poliklinik für Kinder- und Jugendmedizin, [K.L., E.G., M.J.K., D.E.M.-W.], Medizinische Kernklinik und Poliklinik [C.B.], and Institut für Medizinische Mikrobiologie und Immunologie [I.S., R.L.] Universtität Hamburg, Universitätsklinikum Hamburg-Eppendorf, Hamburg, Germany; Department of Pediatrics [M.B.], Wake Forest University School of Medicine, Winston-Salem, North Carolina; and Institut für Hygiene und Mikrobiologie der Universität Würzburg [H.K.], Würzburg, Germany

\section{ABSTRACT}

\begin{abstract}
Saliva antibodies to Escherichia coli $\mathrm{O} 157$ were investigated as markers of the immune response in children with enteropathic hemolytic uremic syndrome (HUS). Paired serum and saliva samples were collected from 22 children with HUS during acute disease and convalescence and were tested for E. coli $\mathrm{O} 157$ lipopolysaccharide (LPS)-specific $\operatorname{IgM}$ and $\operatorname{IgA}$ antibodies by ELISA. Serum and saliva samples from 44 age-matched controls were used to establish the cut-off values. Elevated levels of IgM and/or IgA antibodies to O157 LPS were detected in saliva of 13/13 HUS patients with Shiga toxin-producing E. coli (STEC) O157 in stool culture and from 4 of 5 HUS patients in whom STEC were not detected. These results closely mirrored the results obtained with paired serum samples. In contrast, saliva and serum samples from four children with STEC isolates belonging to O-groups $\mathrm{O} 26, \mathrm{O} 145(n=2)$, and O165 lacked detectable O157 LPS-specific antibodies. The specificity of the ELISA was confirmed by western blotting. In STEC O157
\end{abstract}

culture-confirmed cases, the sensitivity of the ELISA was $92 \%$ for saliva IgM and IgA, based on the first available sample, and $100 \%$ and $92 \%$, respectively, when subsequent samples were included. The specificity was $98 \%$ for $\operatorname{IgM}$ and $100 \%$ for $\operatorname{IgA}$. Children with E. coli O157 HUS demonstrate a brisk, easily detectable immune response as reflected by the presence of specific antibodies in their saliva. Saliva-based immunoassays offer a reliable, noninvasive method for the diagnosis of $E$. coli O157 infection in patients with enteropathic HUS. (Pediatr Res 52: 307-313, 2002)
Abbreviations
HUS, Hemolytic uremic syndrome
STEC, Shiga toxin-producing Escherichia coli
Ig, Immunoglobulin
LPS, Lipopolysaccharide
ELISA, Enzyme linked immunosorbent assay

The clinical spectrum of STEC, especially of prototypic $E$. coli $\mathrm{O} 157$ strains, includes mild diarrhea, hemorrhagic colitis, and the classical (enteropathic) HUS ( $\left.\mathrm{E}^{+} \mathrm{HUS}\right)(1-3) . \mathrm{E}^{+} \mathrm{HUS}$ occurs predominantly in young children and in the elderly possibly because of a lack of immunity in these age groups (3, 4). It is characterized by a prodrome of gastroenteritis, frequently with bloody diarrhea, followed by acute microangiopathic hemolytic anemia, thrombocytopenia, and acute renal failure. Occasionally, other organs are also affected $(4,5) . \mathrm{E}^{+}$

Received May 8, 2001; accepted August 22, 2001.

Correspondence and reprint requests: Dr. Kerstin Ludwig, Klinik und Poliklinik für Kinder- und Jugendmedizin, Universitätsklinikum Hamburg-Eppendorf, Martinistr. 52, 20246 Hamburg, Germany; e-mail: kludwig@uke.uni-hamburg.de

DOI: 10.1023/01.PDR.0000020086.66597.3A
HUS accounts for approximately $50 \%$ of acute renal failure in young children $(4,6)$. Outbreaks and sporadic infections by $E$. coli $\mathrm{O} 157$ have been reported from all inhabited continents (6). The largest recorded outbreak of E. coli $\mathrm{O} 157$ to date occurred in Sakai City (Japan) in 1996. It led to 12,680 cases of diarrhea and 121 of HUS and dramatically illustrated the pathogenic potential and public health importance of this organism (7). It also demonstrated the continuing need for simple and rapid diagnostic techniques.

The detection of IgM and IgA, and IgG antibodies to STEC LPS O157, but also to non-O157 LPS in serum samples, has emerged as a useful and reliable diagnostic method (8-13), especially when the bacterial isolation fails $(13,14)$. Two preliminary reports proposed the measurement of saliva anti- 
bodies for the diagnosis of infections by $E$. coli $\mathrm{O} 157(15,16)$. The objective of the current study was therefore to investigate the occurrence and dynamics of the immune response to E. coli O157 LPS in children with HUS as reflected by saliva antibodies and to further explore the utility of a saliva-based, rapid and noninvasive diagnostic technique.

\section{METHODS}

Patients and controls. Between November 1996 and September 199922 consecutive patients 0.9 to 14.3 years of age (median 3.5 years; mean \pm SD: $4.3 \pm 3.2$ years) with enteropathic HUS from the Children's Hospital, University of Hamburg were investigated for saliva and serum antibodies against E. coli O157 LPS. HUS was defined as the triad of microangiopathic hemolytic anemia, thrombocytopenia, and acute renal failure according to the criteria of Fong et al. (17). Four additional patients with HUS were excluded from the study because of missing consent or incomplete samples. Twelve patients were female. All 22 patients presented with diarrhea, which was bloody in 20 cases. Nine patients $(41 \%)$ were dialyzed, eight underwent peritoneal dialysis for 5 to $43 \mathrm{~d}$ (median $9 \mathrm{~d}$; mean $\pm \mathrm{SD}: 13 \pm 11 \mathrm{~d}$ ), and one received hemodialysis for $9 \mathrm{~d}$. Eighteen patients received at least one packed red cell transfusion. None of the patients received plasma preparations. For each patient, two age-matched healthy controls $(n=44)$ were identified during the same time period from various kindergartens and from the endocrinology clinic of the Poliklinik für Kinder- und Jugendmedizin. Blood was drawn from these children for evaluation of their immune status before hepatits B immunization or for delayed or accelerated growth. Their saliva and serum samples were used to establish normal cut-off levels. None of the controls had recent diarrhea or was related to HUS cases. The project has been approved and was conducted in accordance to the ethical guidelines for the Children's Hospital Hamburg-Eppendorf. Parental informed consent was obtained for all children studied.

Serum and saliva samples. A total of 119 paired saliva and serum samples were simultaneously collected from 22 HUS patients during acute and convalescent stages of the disease. The first sample pair was obtained 5 to $21 \mathrm{~d}$ after the onset of diarrhea (median $8 \mathrm{~d}$; mean \pm SD: $8.5 \pm 3.7 \mathrm{~d}$ ), which corresponded to $4 \mathrm{~d}$ before to $10 \mathrm{~d}$ after the clinical manifestation of HUS (median $1 \mathrm{~d}$; mean $\pm \mathrm{SD}$ : $1.5 \pm 2.7 \mathrm{~d}$ after HUS). Follow-up sample pairs were collected 7 to $761 \mathrm{~d}$ (median $24 \mathrm{~d}$; mean \pm SD: $77 \pm 121 \mathrm{~d}$ ) after the onset of diarrhea. Fourteen additional saliva samples were collected during the acute HUS without corresponding serum samples.

For the collection of saliva, a small absorbent pad (Rauscher, Pattensen, Germany) was placed between the patient's cheek and gum. From each patient, at least two pads were used to obtain a minimum of $500 \mu \mathrm{L}$ saliva. All samples were processed within $30 \mathrm{~min}$ after receipt. The pads were centrifuged at $13,000 \mathrm{~g}$ in a microliter tube. The supernatant was stored at $-20^{\circ} \mathrm{C}$ until analyzed.

E. coli O157 LPS ELISA for saliva and serum samples. LPS from E. coli $\mathrm{O} 157: \mathrm{H}-$ strain 493-1, from a child with
HUS, was extracted by hot phenol water as described by Westphal and Jann (18). Microtiter plates (96-well format Immunoplates, Nunc, Roskilde, Denmark) were coated with $0.5 \mu \mathrm{g}$ O157 LPS per well diluted in $10 \mathrm{mM}$ PBS. LPS ELISA plates were interchangeably used for saliva and serum antibody studies. Serum samples were diluted 1:500 in PBS containing $0.1 \%$ Tween-20 (Merck, Darmstadt, Germany) and 2\% fetal bovine serum (Linaris, Bettingen am Main, Germany) and were tested for IgM and IgA antibodies against E. coli $\mathrm{O} 157$ LPS as published previously (10).

Saliva samples were diluted $1: 10$ in PBS containing $0.1 \%$ Tween-20 and $0.5 \%$ fetal bovine serum (Linaris, Bettingen am Main, Germany) added to triplicate wells and incubated at $37^{\circ} \mathrm{C}$ for $2 \mathrm{~h}$. Wells were extensively washed with PBSTween-20 1\%. Optimized dilutions of rabbit anti-human IgM (1:2000) or IgA (1:9000) alkaline-phosphatase conjugated antibodies (Sigma Chemical Co. Chemicals, St. Louis, MO, USA), in PBS-Tween $0.1 \%$ with $0.5 \%$ fetal bovine serum, were added to the wells for $60 \mathrm{~min}$ at $37^{\circ} \mathrm{C}$. p-Nitrophenyl Phosphate (Sigma Chemical Co. Chemicals, St. Louis, MO, USA) was used as substrate. The reaction was stopped with 50 $\mu \mathrm{L} 2 \mathrm{~N} \mathrm{NaOH}$ after $30 \mathrm{~min}$ at $37^{\circ} \mathrm{C}$. The $\mathrm{A}_{405}$ was recorded against a blank well containing substrate solution and $2 \mathrm{~N}$ $\mathrm{NaOH}$. All saliva samples from patients and controls were tested at least twice for IgM and IgA antibodies. To establish the sensitivity and specificity of the ELISA, homologous antiO157 LPS and heterologous non-O157 LPS sera from rabbits were used, respectively. The breakpoints were defined as the mean absorbency plus $3 \mathrm{SD}$ of the control specimens as described previously $(10,11)$. Previously defined serum and saliva samples were run with each assay as positive and negative controls. No difference was observed between the mean optical densities of saliva IgM or IgA anti-E. coli O157 LPS antibodies of control children younger $(n=30)$ and older than 5 years of age $(n=14)$; $t$ tests for unpaired samples were performed without a significant result for both (IgM and $\operatorname{IgA}$ ) ELISA (the normality assumption was tested by KolmogoroffSmirnoff test).

E. coli 0157 immunoblot for saliva and serum samples. Selected serum samples, especially those with a weak antibody response by ELISA, were also tested for IgM antibodies by immunoblotting as described (9) using the same O157 LPS preparation. E. coli O157 LPS was separated by SDSpolyacrylamide gel electrophoresis (SDS-PAGE) and transferred to nitrocellulose membranes (Protran BA85 Cellulose Membrane, Schleicher and Schuell, Dassel, Germany) by electroblotting. Membranes were blocked and cut into strips that were incubated with diluted serum $(1: 100)$ or saliva $(1: 10)$ for $2 \mathrm{~h}$ at room temperature. Bound Igs were detected using 1:5000 dilutions of alkaline-phosphatase-conjugated rabbit antihuman IgM or IgA (Sigma Chemical Co. Chemicals, St. Louis, MO, USA). Previously defined serum samples and saliva samples were run with each assay as positive and negative controls.

STEC isolation and stx genotyping. Stool samples were collected 5 to $22 \mathrm{~d}$ (median $9 \mathrm{~d}$ ) after the onset of the diarrhea and examined for STEC, including E. coli O157, and traditional enteropathogenic E. coli. STEC O157 were isolated 
using sorbitol-MacConkey agar and immunomagnetic separation $(19,20)$. Sorbitol-negative colonies were confirmed biochemically as E. coli and tested for the presence of $\mathrm{O} 157$ antigen using a latex slide agglutination test (Oxoid, Wesel, Germany) (19). To detect non-O157 STEC strains, colony sweeps from primary stool cultures on sorbitol-MacConkey agar were screened directly for the presence of $s t x_{1}$ and $s t x_{2}$ gene sequences. The detection of the $s t x_{1}$ and $s t x_{2}$ genes from E. coli $\mathrm{O} 157$ and non-O157 strains by PCR was done by using primers KS7/KS8 (21) and GK3/GK4 (22), respectively, according to published methods (23). To identify STEC strains from PCR positive stool samples and to determine the stx genotype, 100 to 200 colonies from each plate were tested by colony blot hybridization with digoxigenin-labeled DNA probes (23). Differentiation of $s t x_{2}$ and $s t x_{2 c}$ genes was performed by the restriction endonuclease analysis of the PCR products as described by Rüssmann et al. (24). O:H serotyping was performed as previously described (25).

Free fecal Shiga toxin. Stool filtrates from all 22 HUS patients were investigated for the presence of free fecal cytotoxicity using vero cell monolayers (2).

Statistical methods. $t$ test, $\chi^{2}$ test, and Spearman's rank correlation (rho), were used as indicated. Descriptive measures were the correlation coefficient and the Spearman's rho; the latter was used to test the correlation for significance. Statistical testing was performed using SPSS version 10.0 (SPSS, Inc., Chicago, IL, USA) on a standard PC.

\section{RESULTS}

Microbiological studies. STEC were identified in stool samples of 17 out of $22(77 \%)$ patients. Thirteen of the isolates belonged to serogroup $\mathrm{O} 157$ and four to E. coli serogroups O26, O145 $(n=2)$, and O165, respectively (Table 1). Free fecal Stx (FStx) was demonstrated in stool filtrates of all 17 patients with STEC $\mathrm{O} 157$ and non-O157 associated HUS. None of the stool filtrates of the five patients lacking STEC isolates showed free cytotoxic activity. Ten of 13 E. coli $\mathrm{O} 157$ isolates harbored the $s t x_{2}$ gene, two the $s t x_{1}$ genes, and in one case the genotype could not be determined. The non-O157 E. coli isolates carried the $s t x_{1}$ gene (E. coli $\mathrm{O} 26$ and one E. coli $\mathrm{O} 145$ isolate), the $s t x_{2}$ gene (E. coli O145), or the $s t x_{2}$ and $s t x_{2 c}$ genes (E. coli O165).

Table 1. E. coli O157 LPS IgM and IgA antibodies in serum and saliva*

\begin{tabular}{lcrrrrr}
\hline & \multirow{2}{*}{$\begin{array}{c}\text { Patients } \\
\text { Isolate }\end{array}$} & \multicolumn{2}{c}{ Serum } & & \multicolumn{2}{c}{ Saliva } \\
\cline { 3 - 4 } \cline { 6 - 7 } & $(n)$ & $\operatorname{IgM}$ & $\operatorname{IgA}$ & & $\operatorname{IgM}$ & $\operatorname{IgA}$ \\
\hline E. coli O157 & 13 & 13 & $12^{* *}$ & & 13 & $12^{* *}$ \\
E. coli O26 & 1 & 0 & 0 & & 0 & 0 \\
E. coli O145 & 2 & 0 & 0 & & 0 & 0 \\
E. coli O165 & 1 & 0 & 0 & & 0 & 0 \\
Negative & 5 & 4 & 4 & & 4 & 4 \\
\hline
\end{tabular}

* Cumulative results of sequential samples, drawn in the first and second week after the onset of HUS are shown.

** Eleven patients showed anti-O157 IgA in sequential samples in serum as well as in saliva, while two patients had either anti-O157 IgA in serum or in saliva.
E. coli 0157 LPS antibody detection in saliva and serum samples. Immunoblot results compared favorably with the ELISA results for detecting anti-O157 LPS IgM and IgA antibodies in serum and saliva samples. An example is shown in Figure 1 with an immunoblot for serum and saliva samples from one patient with $E$. coli O157- associated enteropathic HUS (Fig. 1, lanes 5 and 6) $(26,27)$.

Breakpoints for the E. coli O157 LPS IgM and IgA ELISA were established using saliva and serum samples from agematched controls as defined in the methods section. For saliva, the $\mathrm{A}_{405}$ values for the ELISA ranged from 0.000 to 0.095 for $\operatorname{IgM}$, and from 0.000 to 0.026 for IgA. The level of significance (mean plus $3 \mathrm{SD}$ of the controls) was 0.042 for IgM and 0.035 for IgA, respectively. For serum, the $\mathrm{A}_{405}$ values for the ELISA ranged from 0.000 to 0.375 for IgM and from 0.000 to 0.060 for IgA. The level of significance (mean plus $3 \mathrm{SD}$ of the controls) was 0.400 for IgM and 0.030 for IgA, respectively.

Acute phase saliva samples (first and second samples, collected all in the first week after the onset of HUS) of all 13 patients with $E$. coli $\mathrm{O} 157$ isolates revealed optical densities in the IgM ELISA exceeding the cut-off level. Twelve of 13 acute saliva samples also had elevated IgA antibodies to E. coli $\mathrm{O} 157$ LPS (Table 1). In addition, four of the five culture-negative cases were positive for saliva IgM and IgA antibodies against E. coli $\mathrm{O} 157$. These results closely mirrored the detection of $E$. coli O157 LPS-specific IgM and IgA in the corresponding serum samples (Table 1). A good correlation was observed between stool culture results and the detection of anti-O157 LPS antibodies (IgM and/or IgA) both in serum and saliva ( $p$

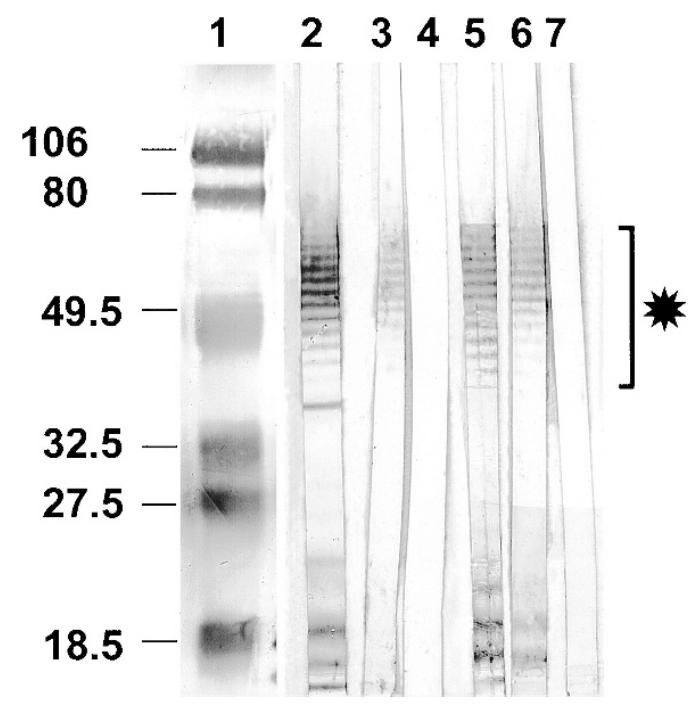

Figure 1. Immunoblot with E. coli O157 LPS as antigen. Blots (lanes): lane 1, low-molecular-weight protein standard (Rainbow prestained; BioRad, Ca, USA) demonstrating the molecular weight in kilo Dalton; lane 2, Rabbit anti-E. coli LPS immune serum, used as positive control; lane 3, positive human control serum; lane 4, negative human control serum. Serum (lane 5) and paired saliva (lane 6) from a child with acute HUS; lane 7, saliva from an age-matched healthy control. Blots were developed with HRP-conjugated anti-rabbit IgG (lane 2) or anti-human IgM (lanes 3-7). The orderly spaced bands, indicated by the bracket and the asterisk, represent LPS molecules having different numbers of repeating units in the O-side chains (26). Note that the molecular weight markers of proteins do not reflect the size of LPS in SDS-PAGE of LPS (27). 
$=0.01 ; \chi^{2}$ test). Furthermore, a good correlation was found between the $A_{405}$ value of all 119 paired saliva and serum samples from all 22 HUS patients with a correlation coefficient of 0.569 for IgM and $r=0.650$ for IgA. Using the Spearman's rank correlation (rho) it was calculated to be 0.751 for IgM and 0.592 for $\operatorname{IgA}(p<0.01$ for both; Spearman's rho).

When only initial saliva samples of patients who manifest antibody to $\mathrm{O} 157$ in their respective sera ( $\geq 3 \mathrm{SD}$ above the mean of healthy controls) were evaluated, a positive correlation was found for $\operatorname{IgA}(r=0.642 ; p<0.01)$, but not for $\operatorname{IgM}$ (Spearman's rank correlation; Fig. $2 A$ and $B$ ). The correlation of positive serum samples ( $\geq 3 \mathrm{SD}$ above the mean of healthy controls) to the paired saliva samples for follow-up samples was $r=0.361$ for $\operatorname{IgM}(n=50)$, and $r=0.540$ for $\operatorname{IgA}(n=$ 30) (Spearman's rho; $p<0.01$ for both) (Fig. $2 C$ and $D$ ). However, of all 17 HUS patients showing elevated IgM antibodies in their first serum samples, $15(88 \%)$ had also elevated IgM antibodies in the corresponding saliva sample. Two additional patients showed increased anti-O157 IgM in their follow-up saliva samples. Of 14 HUS patients showing elevated IgA antibodies in their first serum sample, 11 (79\%) had also elevated IgA antibodies in the corresponding saliva sample, while one also remained negative in follow-up saliva samples, and two showed measurable anti-O157 IgA in follow-up saliva samples.

Two patients showed an IgA seroconversion, i.e. changing from negative to positive ELISA results in serum samples during follow-up. Both patients were already positive for IgA in their first saliva sample.

None of the patients with non-O157 STEC isolates showed elevated anti-O157 LPS saliva or serum antibodies (Table 1) confirming the specificity of both serum and saliva ELISA. The sensitivity of the saliva O157 LPS ELISA, calculated from the STEC 0157 culture-confirmed cases $(n=13)$, was $100 \%$ for IgM and $92 \%$ for IgA (Table 1) for all samples (initial and follow-up samples). For the first collected saliva sample, the sensitivity was $92 \%$ for $\operatorname{IgM}$ and $\operatorname{IgA}$, respectively.

The first available saliva sample, collected 5 to $21 \mathrm{~d}$ after the onset of diarrhea (median $8 \mathrm{~d}$ ), which corresponded to $4 \mathrm{~d}$ before to $10 \mathrm{~d}$ after the clinical manifestation of HUS (median $1 \mathrm{~d}$; mean \pm SD: $1.5 \pm 2.7 \mathrm{~d}$ ), showed in all but one instance $(n=16) E$. coli O157 LPS-specific IgM and/or IgA. In 13 of 17 patients with O157-associated HUS (13 confirmed by culture, 4 by serology), the first available saliva sample was positive for both IgM and IgA anti-O157 LPS. Conversion of saliva anti-O157 LPS IgM and IgA was observed as late as
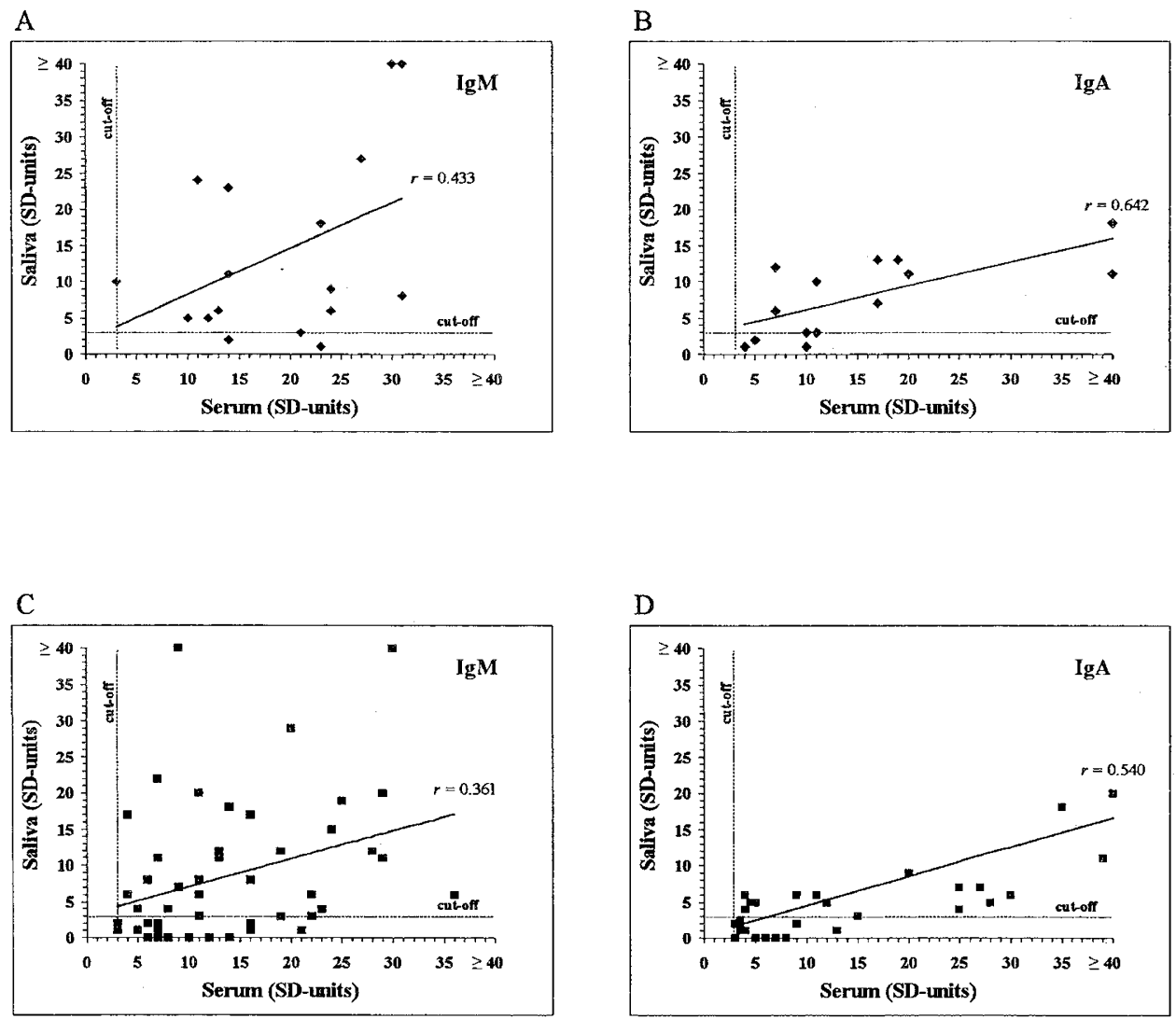

Figure 2. Results represent all serum samples showing elevated E. coli O157 LPS-specific IgM or IgA levels ( $\geq 3$ SD above the mean of healthy controls) measured by ELISA in correlation to the paired saliva samples. Initial serum samples showing antibodies for IgM $(A)$ and for IgA $(B)$, and follow-up samples having detectable $\operatorname{IgM}(C)$, and $\operatorname{IgA}(D)$ in serum samples in correlation to the corresponding saliva samples. A positive correlation was found for IgA for initial and follow-up samples and for follow-up samples of IgM (all three $p<0.01$; Spearman's rho), but data were not significant for IgM for initial samples. Results are presented as SD-units as described in the Methods section. The cut-off level for positive ELISA readings was set at 3 SD above the mean of control samples for both assays. Breakpoints of the $\mathrm{A}_{405}$ values were 0.042 and 0.035 for saliva $\operatorname{IgM}$ and $\operatorname{IgA}$, respectively, and 0.400 and 0.030 for serum $\operatorname{IgM}$ and $\operatorname{IgA}$, respectively. $\bullet$, initial samples; $\mathbf{\square}$, follow-up samples. 
$21 \mathrm{~d}$ after the onset of diarrhea in one case (which corresponded to $1 \mathrm{wk}$ after the onset of HUS). Two of three remaining patients demonstrated either conversion of saliva $\operatorname{IgM}(6 \mathrm{~d}$ after the onset of HUS) or saliva IgA ( $13 \mathrm{~d}$ after the onset of HUS) (Fig. 3), while one patient remained negative for anti-O157 IgA in saliva also during follow-up.

Saliva anti-O157 LPS antibody levels peaked 1 to $3 \mathrm{wk}$ after the onset of diarrhea, median $11 \mathrm{~d}[\operatorname{IgM}]$, and $10 \mathrm{~d}$ [IgA].

Examples of four individual saliva IgM and IgA antibody kinetics are shown in Fig. 4.

One out of $44(2.3 \%)$ control children had elevated saliva IgM; another revealed slightly elevated serum IgA antibodies. None of the control samples showed increased saliva IgA or serum IgM antibodies. The specificity of the saliva-based O157 LPS ELISA, based on the results obtained with the samples from the control children and from the patients with non-O157 isolates, was $98 \%$ for salivary IgM and $100 \%$ for salivary IgA.

\section{DISCUSSION}

Infection by E. coli $\mathrm{O} 157$ induces a vigorous immune response that is reflected in an acute rise of serum levels of O-group-specific IgA, IgM and, although less consistently, IgG antibodies $(8,10,11,28)$. Here we show that children with $E$. coli $\mathrm{O} 157$-associated HUS also demonstrate easily detectable salivary IgM and IgA class antibodies. Specifically, saliva samples of all 13 patients with $E$. coli $\mathrm{O} 157$ isolate and $3 \mathrm{HUS}$ patients with serological evidence of E. coli $\mathrm{O} 157$ infection,
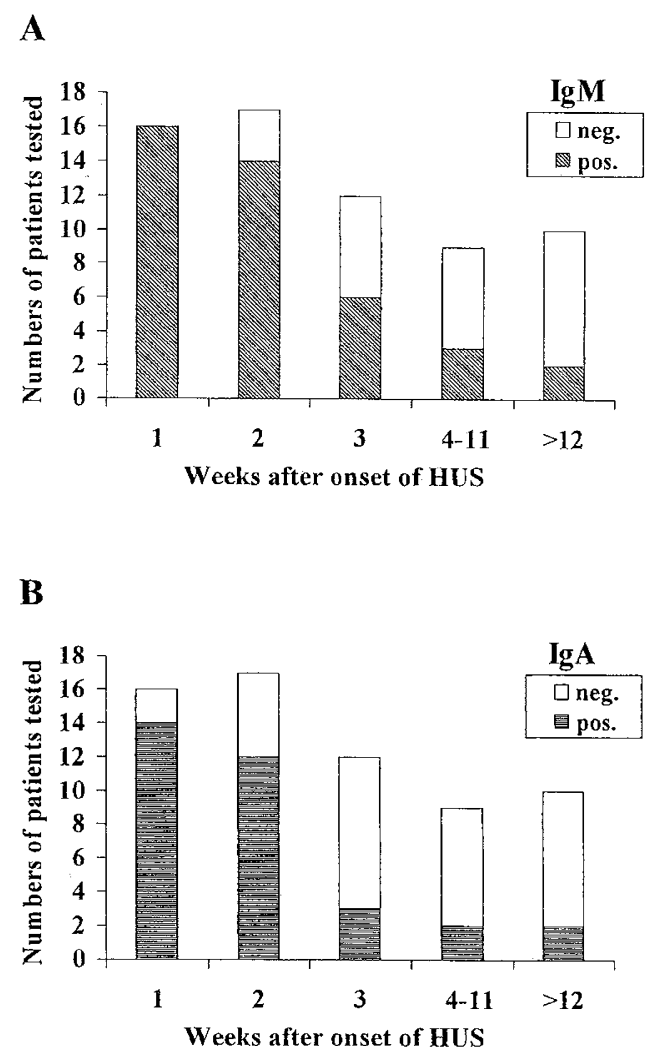

Figure 3. Saliva anti-O157 LPS IgM and IgA antibody reactivity of the $17 \mathrm{E}$. coli $\mathrm{O} 157$-associated HUS cases (13 culture-confirmed and 4 confirmed by elevated anti-O157 LPS antibodies in serum samples) relative to the onset of HUS. Results represent all patients tested at the respective intervals. collected in the first week after the onset of HUS, showed elevated IgM by ELISA (Fig. 3). Fourteen of these samples were also positive for E. coli O157 LPS-specific IgA (Fig. 3). We further show that salivary antibodies can be conveniently measured and used for serodiagnostic purposes. Specific antibodies have been demonstrated previously in saliva from patients with viral, bacterial, and parasitic infections (29-33). Preliminary data, presented first by our laboratory (15) and by Chart and Jenkins (16), suggested the potential merit of this approach in patients with E. coli $\mathrm{O} 157$ infections. The aim of the present study was to systematically investigate whether saliva would be suitable for the diagnosis of infections by $E$. coli $\mathrm{O} 157$ in children with HUS using an indirect immunoenzyme assay. Here we report that E. coli O157 LPS IgM and/or IgA can be reliably detected in "acute" saliva from patients with HUS secondary to E. coli O157. In fact, we observed a close correlation between serum and saliva anti-E. coli $\mathrm{O} 157$ antibodies $(p<0.01$; Spearman's rank correlation). Furthermore, paired serum and saliva samples from patients with non-O157 stool isolates yielded negative O157 LPS ELISA results, demonstrating once more the specificity of the assay. It is of note that Chart and Jenkins (16) reported a positivity rate in saliva samples of $62 \%(13 / 21)$ patients with anti-O157 LPS antibodies in serum samples. In our patient population $88 \%$ $(15 / 17)$, patients showing elevated IgM antibodies in their first serum samples had also detectable IgM in the corresponding saliva samples. The apparent discrepancy to our findings may be due to varied reasons, e.g. the timing of the sample collection, the underlying disease (HUS versus hemorrhagic colitis), or the transportation conditions of saliva samples. All three items were addressed in our current study. All except one saliva sample was collected within 1 wk after the onset of HUS, they were processed within a short period of time, and the study was restricted to HUS patients. For diagnostic purposes, we recommend measurement of the IgM antibody response in saliva samples in the first week after the onset of HUS, which usually corresponds to the second or third week after the onset of diarrhea, based on the investigations reported in this paper. Additional samples can be investigated a week later if the first sample is equivocal. Occasionally, sequential saliva sampling may increase the yield of positive samples. This was demonstrated in our study in two patients, with negative IgM antibodies initially, while subsequent samples showed an anti-O157 antibody response, collected 6 and $7 \mathrm{~d}$, respectively, after the onset of HUS.

The reason for the correlation for the O157 LPS-specific IgM ELISA for the first positive serum samples to the corresponding saliva samples being not significant was the wide spread of $\mathrm{A}_{405}$ values in saliva as it is shown in Figure $2 \mathrm{~A}$, expressed in SD-units. The results of the present study are encouraging in that they suggest that the use of a simple, noninvasive method, namely saliva sampling, may replace more traditional serological techniques in the setting of $\mathrm{E}^{+}$ HUS. This approach offers a valuable alternative in small — and often severely anemic - children. Furthermore, it may be used as a convenient screening tool for epidemiologic studies, e.g. in outbreaks, and the evaluation of vaccine trials. Future studies are necessary to explore the applicability of saliva-based se- 

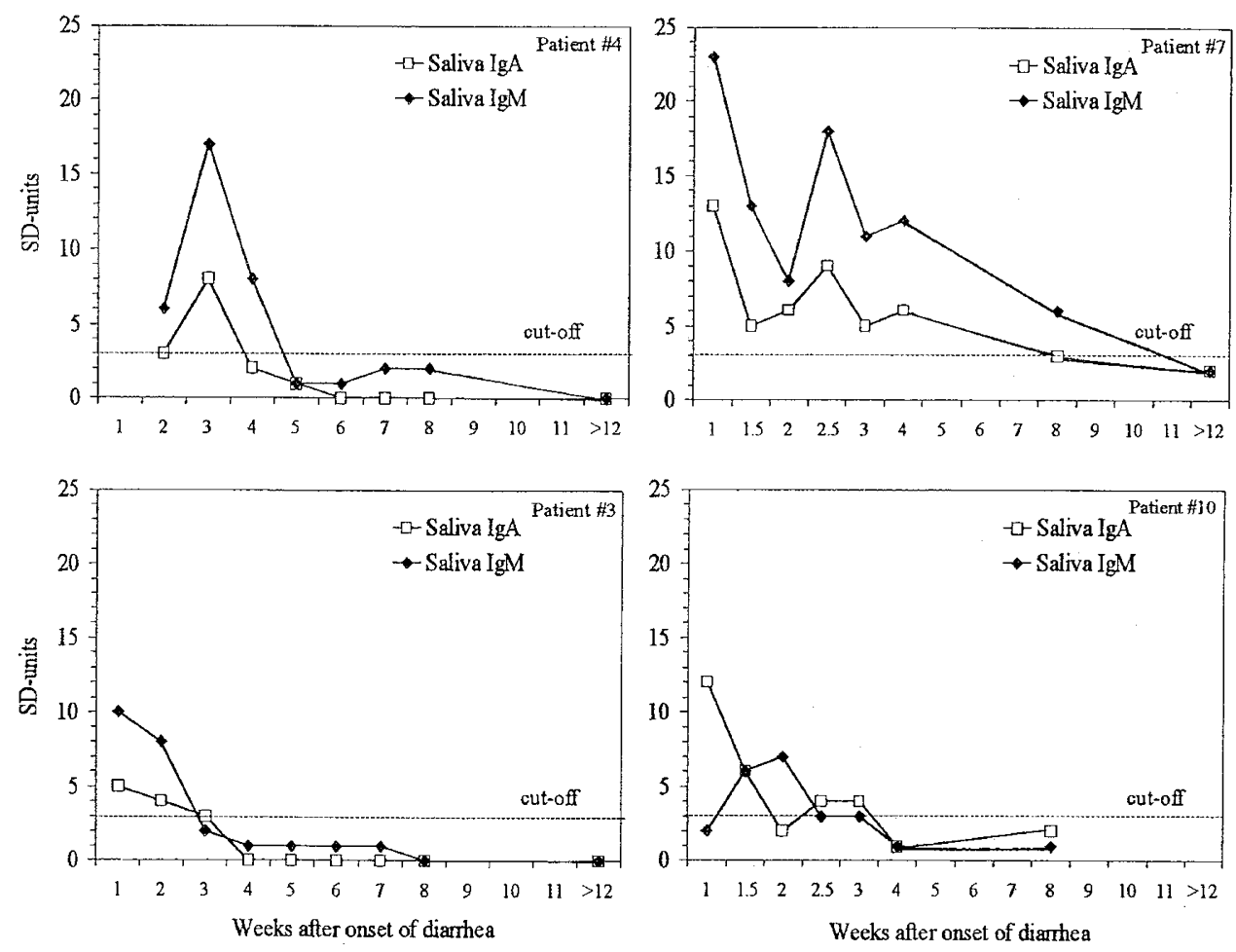

Figure 4. Individual kinetics of E. coli O157 LPS specific saliva IgA and IgM antibodies in children with enteropathic HUS. The cut-off levels for positive ELISA readings were defined as $3 \mathrm{SD}$-units above the mean of the controls for both assays. Results are presented as SD-units as described in the Methods section. Breakpoints of the $\mathrm{A}_{405}$ values were 0.042 and 0.035 for saliva IgM and IgA, respectively, and 0.400 and 0.030 for serum IgM and IgA, respectively.

rology in patients with hemorrhagic colitis and contacts of HUS patients. As with the detection of serum antibodies to $E$. coli $\mathrm{O} 157$, the utility of this method depends on the predominance of $E$. coli $\mathrm{O} 157$ in many regions. The induction of saliva antibodies by emerging non-O157 STEC serotypes, belonging to $E$. coli O-groups 26 and 111 , among others $(11,34-38)$, appears likely, but has yet to be shown.

Acknowledgments. We thank Maike Westphal for excellent technical assistance. The help of Prof. Paul-Michael Kaulfers in preparation of the LPS is gratefully acknowledged. The help of colleagues (Dr. Hans Altrogge, Dr. Kirsten Timmermann, and Dr. Melanie Dietz) and the staff nurses of pediatric nephrology unit, Hamburg, in patient care and sample collection is gratefully acknowledged. Part of this work appears in the doctoral thesis of Enke Grabhorn.

\section{REFERENCES}

1. Riley LW, Remis RS, Helgerson SD, McGee HB, Wells JG, Davis BR, Hebert RJ, Olcott ES, Johnson LM, Hargrett NT, Blake PA, Cohen LM 1983 Hemorrhagic colitis associated with a rare Escherichia coli serotype. N Engl J Med 308:681-685

2. Karmali MA, Steele BT, Petric M, Lim C 1983 Sporadic cases of hemolytic uremic syndrome associated with fecal cytotoxin and cytotoxin-producing Escherichia coli. Lancet 1:619-620

3. Carter AO, Borczyk AA, Carlson JAK, Harvey B, Hockin JC, Karmali MA, Krishnan C, Korn DA, Lior H 1987 A severe outbreak of Escherichia coli O157:H7-associated hemorrhagic colitis in a nursing home. N Engl J Med 317:1496-1500

4. Karmali MA 1989 Infection by verocytotoxin-producing Escherichia coli. Clin Microbiol Rev 2:15-38

5. Gallo EG, Gianantonio CA 1995 Extrarenal involvement in diarrhoea-associated haemolytic-uraemic syndrome. Pediatr Nephrol 9:117-119

6. Griffin PM, Tauxe RV 1991 The epidemiology of infectious caused by Escherichia coli $\mathrm{O} 157: \mathrm{H7}$, other enterohemorrhagic E. coli, and the associated hemolytic uremic syndrome. Epidemiol Rev 13:60-98
7. Fukushima H, Hashizume T, Morita Y, Tanaka J, Azuma K, Mizumoto Y, Kaneno M, Matsuura M, Konma K, Kitani T 1999 Clinical experiences in Sakai City Hospital during the massive outbreak of enterohemorrhagic Escherichia coli O157 infections in Sakai City, 1996. Pediatr Int 41:213-217

8. Chart H, Smith HR, Scotland SM, Rowe B, Milford DV, Taylor CM 1991 Serological identification of Escherichia coli $\mathrm{O} 157: \mathrm{H} 7$ infection in haemolytic uraemic syndrome. Lancet 337:138-140

9. Bitzan M, Moebius E, Ludwig K, Müller-Wiefel DE, Heesemann J, and Karch H 1991 High incidence of serum antibodies to Escherichia coli O157 lipopolysaccharide in children with hemolytic uremic syndrome. J Pediatr 119:380-385

10. Bitzan M, Ludwig K, Klemt M, König H, Büren J, Müller-Wiefel DE 1993 The role of Escherichia coli $\mathrm{O} 157$ infections in the classical (enteropathic) haemolytic uraemic syndrome: results of a Central European, multicentre study. Epidemiol Infect 110:183-196

11. Ludwig K, Bitzan M, Zimmermann S, Kloth M, Ruder H, Müller-Wiefel DE 1996 Immune response to non-O157 Vero toxin-producing Escherichia coli in patients with hemolytic uremic syndrome. J Infect Dis 174:1028-1039

12. Tarr PI, Neill MA 1996 Perspective: the problem of non-O157:H7 Shiga toxin (Verocytotoxin)-producing Escherichia coli [comment]. J Infect Dis 174:1136-1139

13. Karch H, Bielaszewska M, Bitzan M, Schmidt H 1999 Epidemiology and diagnosis of Shiga toxin-producing Escherichia coli infections. Diagn Microbiol Infect Dis 34:229-243

14. Tarr PI, Neill MA, Clausen CR, Watkins SL, Christie DL, Hickman RO 1990 Escherichia coli O157:H7 and the hemolytic uremic syndrome: importance of early cultures in establishing the etiology. J Infect Dis 162:553-556

15. Ludwig K, Grabhorn E, Müller-Wiefel DE 1998 Salivary IgA and IgM antibodies to Escherichia coli $\mathrm{O} 157$ lipopolysaccharide in children with hemolytic uremic syndrome (HUS) and family members. In: Abstracts of the 8th International Congress of Infectious Diseases; May 15-18, 1998; Boston, MA, pp 283

16. Chart H, Jenkins C 1998 Salivary antibodies to lipopolysaccharide antigens of Escherichia coli $\mathrm{O} 157$ [letter]. Lancet 352:371

17. Fong JS, de Chadarevian JP, Kaplan BS 1982 Hemolytic uremic syndrome: current concepts and management. Pediatr Clin North Am 29:835-856

18. Westphal O, Jann K 1965 Bacterial lipopolysaccharides: extraction with phenol-water and further applications of procedure. Methods Carbohydr Chem 5:83-91

19. March SB, Ratnam S 1986 Sorbitol-MacConkey medium for detection of Escherichia coli $\mathrm{O} 157: \mathrm{H} 7$ associated with hemorrhagic colitis. J Clin Microbiol 23:869-872

20. Karch H, Janetzki-Mittmann C, Aleksic S, Datz M 1996 Isolation of enterohemorrhagic Escherichia coli $\mathrm{O} 157$ strains from patients with hemolytic uremic syndrome by using immunomagnetic separation, DNA-based methods, and direct culture. J Clin Microbiol 34:516-519 
21. Schmidt H, Rüssmann H, Schwarzkopf A, Aleksic S, Heesemann J, Karch H 1994 Prevalence of attaching and effacing Escherichia coli in stool samples from patients and controls. Zentralbl Bakteriol 281:201-213

22. Gunzer F, Böhm H, Rüssmann H, Bitzan M, Aleksic S, Karch H 1992 Molecular detection of sorbitol-fermenting Escherichia coli $\mathrm{O} 157$ in patients with hemolyticuremic syndrome. J Clin Microbiol 30:1807-1810

23. Karch H, Huppertz HI, Bockemühl J, Schmidt H, Schwarzkopf A, and Lissner R 1997 Shiga Toxin-producing Escherichia coli Infections in Germany. J Food Prot 60:1454-1457

24. Rüssmann H, Schmidt H, Heesemann J, Caprioli A, Karch H 1994 Variants of Shiga-like toxin II constitute a major toxin component in Escherichia coli $\mathrm{O} 157$ strains from patients with haemolytic uraemic syndrome. J Med Microbiol 40:338-343

25. Aleksic S, Karch H, Bockemühl J 1992 A biotyping scheme for Shiga-like (Vero) toxin-producing Escherichia coli $\mathrm{O} 157$ and a list of serological cross-reactions between O157 and other gram-negative Bacteria. Zentralbl Bakteriol 276:221-230

26. Tsai CM, Frasch CE 1982 A sensitive silver stain for detecting lipopolysaccharides in polyacrylamide gels. Anal Biochem 119:115-119

27. Russell RR, Johnson KG 1975 SDS-polyacrylamide gel electrophoresis of lipopolysaccharides. Can J Microbiol 21:2013-2018

28. Greatorex JS, Thorne GM 1994 Humoral immune responses to Shiga-like toxins and Escherichia coli $\mathrm{O} 157$ lipopolysaccharide in hemolytic-uremic syndrome patients and healthy subjects. J Clin Microbiol 32:1172-1178

29. Parry JV, Perry KR, Mortimer PP 1987 Sensitive Assays for viral antibodies in saliva: an alternative to tests on serum. Lancet 2:72-75

30. Helfand RF, Kebede S, Alexander JP Jr, Wondimagegnehu A, Heath JL, Gary HE Jr, Anderson LJ, Beyene H, Bellini WJ 1996 Comparative detection of measels-specific
IgM in oral fluid and serum from children by antibody-capture IgM ELISA. J Infect Dis $173: 1470-1474$

31. Perry KR, Brown DWG, Parry JV, Panday S, Pipkin C, Richards A 1993 Detection of measles, mumps, and rubella antibodies in saliva using antibody capture radioimmunoassay. J Med Virol 40:235-240

32. Hashkes PJ, Spira DT, Deckelbaum RJ, Granot E 1994 Salivary IgA antibodies to Giardia lamblia in day care center children. Pediatr Infect Dis J 13:953-958

33. Grimwood K, Lund JCS, Coulson BS, Hudson IL, Bishop RF, Barnes GL 1988 Comparison of serum and mucosal antibody responses following severe acute rotavirus gastroenteritis in young children. J Clin Microbiol 26:732-738

34. Caprioli A, Luzzi I, Rosmini F, Resti C, Edefonti A, Perfumo F, Farina C, Goglio A, Gianviti A, Rizzoni G 1994 Community-wide outbreak of hemolytic-uremic syndrome associated with non-O157 verocytotoxin-producing Escherichia coli. J Infect Dis 169:208-211

35. Banatvala N, Debeukelaer MM, Griffin PM, Barrett TJ, Greene KD, Green JH, Wells JG 1996 Shiga-like toxin-producing Escherichia coli O111 and associated hemolyticuremic syndrome: a family outbreak. Pediatr Infect Dis J 15:1008-1011

36. Lopez EL, Prado-Jimenez V, O'Ryan-Gallardo M, Contrini MM 2000 Shigella and Shiga toxin-producing Escherichia coli causing bloody diarrhea in Latin America. Infect Dis Clin North Am 14:41-65

37. Acheson DW, Wolf LE, Park CH 1997 Escherichia coli and the hemolytic-uremic syndrome [letter, comment]. N Engl J Med 336:515

38. Zhang WL, Bielaszewska M, Liesegang A, Tschäpe H, Schmidt H, Bitzan M, Karch H 2000 Molecular Characteristics and Epidemiological significance of Shiga Toxinproducing Escherichia coli O26 strains. J Clin Microbiol 38:2134-2140 